\title{
Case Report \\ Pure Motor Monoparesis in the Leg due to a Lateral Medullary Infarction
}

\author{
Hiromasa Tsuda, Kozue Tanaka, and Shuji Kishida \\ Department of Neurology, Tokyo Metropolitan Cancer and Infectious Diseases Center Komagome Hospital, 3-18-22 Honkomagome, \\ Bunkyo-ku, Tokyo 113-8677, Japan \\ Correspondence should be addressed to Hiromasa Tsuda, hiromasatsuda@cick.jp
}

Received 10 June 2011; Accepted 31 October 2011

Academic Editor: Aaron S. Dumont

Copyright () 2012 Hiromasa Tsuda et al. This is an open access article distributed under the Creative Commons Attribution License, which permits unrestricted use, distribution, and reproduction in any medium, provided the original work is properly cited.

\begin{abstract}
A 76-year-old man with essential hypertension abruptly presented with slight left-sided leg weakness, despite normal strength in the other extremities. Left-sided Babinski's reflex was detected. There were no other neurologic abnormalities. Cranial magnetic resonance imaging demonstrated a small infarction in the lower lateral medulla oblongata on the left side. Cranial magnetic resonance angiography demonstrated an absence of flow of the left vertebral artery. He became asymptomatic within 10 days under intravenous antiplatelet agent. The corticospinal tract fibers innervating the lower extremity caudal to the pyramidal decussation might be involved. We emphasize that this is a first reported case of pure motor monoparesis in the leg due to lateral medullary infarction.
\end{abstract}

\section{Introduction}

Pure motor monoparesis in the leg (PMML) is characterized by weakness limited to unilateral lower limb without other neurological abnormalities, and caused by isolated corticospinal tract deficits $[1,2]$. Regarding responsible infarct lesions for PMML, the cerebral cortex, corona radiata, and internal capsule and pons have been noted $[1,2]$. Here, we report a first case of PMML due to lateral medullary infarction (LMI).

\section{Case Report}

A 76-year-old man with essential hypertension abruptly complained of walking disturbance and was admitted to our hospital on February 2011. In the left lower extremity, Barré's sign was observed, though manual muscle strength testing revealed all normal. In addition, left-sided Babinski's reflex was detected. There were no other abnormalities on the neurological examination. Complete blood cell count and blood chemistry were within normal ranges. Electrocardiogram, echocardiography, and chest X-P findings demonstrated no abnormalities. Cranial magnetic resonance im- aging demonstrated a localized LMI on the left side (Figures $1(\mathrm{a})$ and 1(b)). Cranial magnetic resonance angiography demonstrated an absence of flow of the left vertebral artery (Figure 1(c)). Under intravenous sodium ozagrel at $160 \mathrm{mg} /$ day and the rehabilitation, he became asymptomatic within 10 days.

\section{Discussion}

In LMI, it is well known that various neurological symptoms, such as sensory disturbance, cerebellar ataxia, dizziness, vertigo, nausea, vomiting, Horner's syndrome, skew deviation, ocular tilt reaction, nystagmus, dysarthria, dysphagia, and hiccups commonly occur $[3,4]$. On the other hand, Kameda et al. [4] reported that of the 167 patients of LMI, 11 patients $(7 \%)$ were diagnosed as having Opalski's syndrome, which is defined as LMI case with ipsilateral hemiparesis [4-11]. Opalski's syndrome may be caused by ischemia of the ipsilateral corticospinal tract caudal to the pyramidal decussation [4-11]. Dhamoon et al. [5] described that the regional perfusion failure of the corticospinal tract caudal to the pyramidal decussation might be the result of a hemodynamic mechanism, because this area might be a junctional 


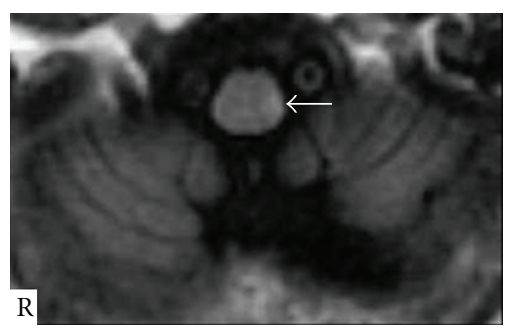

(a)

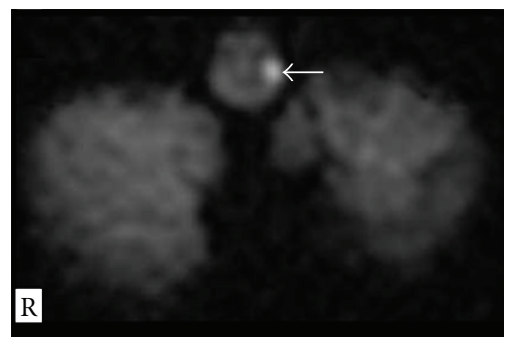

(b)

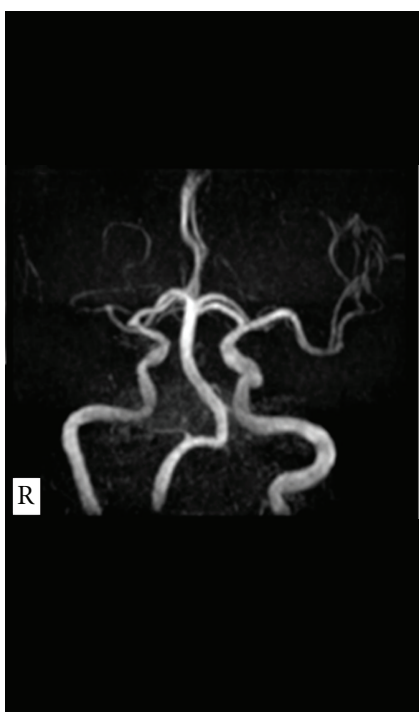

(c)

FIGURE 1: (a) Fluid-attenuated inversion recovery image and (b) diffusion-weighted image of cranial magnetic resonance imaging on the axial images demonstrated a small infarct lesion in the lower lateral medulla oblongata on the left side (arrow). (c) Cranial magnetic resonance angiography demonstrated an absence of flow of the left vertebral artery.

zone between the anterior and posterior spinal artery and between the vertebral and spinal artery supplied. Whereas, regarding the etiology of Opalski's syndrome, the vertebral artery occlusion [6-8] and infarction of the medullary penetrating artery arising from the vertebral artery or anterior spinal artery [9] were also speculated.

Although the somatotopic arrangements of the corticospinal tract in the human brain have been generally elucidated, very little is known about the somatotopy in the medulla oblongata [12, 13]. In 2011, based on the diffusion tensor tractography analysis, Kwon et al. [13] reported that the hand somatotopy of the corticospinal tract was located at the medial portion of the medullary pyramid, in contrast, the leg somatotopy occupied its lateral portion. However, the somatotopic arrangements of the corticospinal tract in the lower medulla oblongata remain unclear.

To date, there was only one reported case of LMI with ipsilateral monoparesis of the leg [9]. Cranial magnetic resonance imaging demonstrated infarction of the medullary penetrating artery secondary to vertebral artery dissection [9]. Therefore, Liu et al. [9] speculated that the corticospinal tract fibers innervating the lower and upper extremities decussate at different levels. Furthermore, vertigo, nystagmus, Horner's syndrome, ataxia in the upper extremity, and alternating hypalgesia were observed in this case [9]. Whereas, in our present patient, though cranial magnetic resonance angiography demonstrated an absence of flow of the left vertebral artery, cranial magnetic resonance imaging demonstrated that a very small infarct lesion in the lower lateral medulla oblongata on the left side. Therefore, we believed that the corticospinal tract caudal to the pyramidal decussation might be involved by atherothrombotic infarction of the medullary penetrating artery or hemodynamic mechanism due to congenital hypoplasia of the left vertebral artery. Regarding the etiology of unilateral leg weakness due to ipsilater- al LMI, we agree with Liu and colleagues' hypothesis [9] that the corticospinal tract fibers innervating the lower and upper extremities decussate at different levels in the lower medulla oblongata. In conclusion, this is a first reported case of PMML due to LMI.

\section{References}

[1] M. Paciaroni, V. Caso, P. Milia et al., "Isolated monoparesis following stroke," Journal of Neurology, Neurosurgery and Psychiatry, vol. 76, no. 6, pp. 805-807, 2005.

[2] A. Hiraga, A. Uzawa, S. Tanaka, K. Ogawara, and I. Kamitsukasa, "Pure monoparesis of the leg due to cerebral infarctions: a diffusion-weighted imaging study," Journal of Clinical Neuroscience, vol. 16, no. 11, pp. 1414-1416, 2009.

[3] J. S. Kim, "Pure lateral medullary infarction: clinical-radiological correlation of 130 acute, consecutive patients," Brain, vol. 126, no. 8, pp. 1864-1872, 2003.

[4] W. Kameda, T. Kawanami, K. Kurita et al., "Lateral and medial madullary infarction. A comparative analysis of 214 patients," Stroke, vol. 34, no. 3, pp. 694-699, 2004.

[5] S. K. Dhamoon, J. Iqbal, and G. H. Collins, "Ipsilateral hemiplegia and the Wallenberg syndrome," Archives of Neurology, vol. 41, no. 2, pp. 179-180, 1984.

[6] J. Montaner and J. Alvarez-Sabín, “Opalski’s syndrome," Journal of Neurology Neurosurgery and Psychiatry, vol. 67, no. 5, pp. 688-689, 1999.

[7] J. García-García, O. Ayo-Martín, and T. Segura, "Lateral medullary syndrome and ipsilateral hemiplegia (Opalski syndrome) due to left vertebral artery dissection," Archives of Neurology, vol. 66, no. 12, pp. 1574-1575, 2009.

[8] M. Y. Cheng and C. Y. Sung, "Opalski syndrome," Acta Neurologica Taiwanica, vol. 14, no. 3, pp. 162-163, 2005.

[9] C. Y. Liu, F. C. Chang, H. H. Hu, and L. C. Hsu, "Ipsilateral crural monoparesis in lateral medullary infarction due to vertebral artery dissection," European Journal of Neurology, vol. 13, no. 7, pp. e8-e9, 2006. 
[10] Y. Kimura, H. Hashimoto, M. Tagaya, Y. Abe, and H. Etani, "Ipsilateral hemiplegia in a lateral medullary infarct-opalski's syndrome," Journal of Neuroimaging, vol. 13, no. 1, pp. 83-84, 2003.

[11] S. Nakamura, M. Kitami, and Y. Furukawa, "Opalski syndrome: ipsilateral hemiplegia due to a lateral-medullary infarction," Neurology, vol. 75, no. 18, p. 1658, 2010.

[12] S. H. Jang, "Somatotopic arrangement and localization of the corticospinal tract in the brainstem of the human brain," Yonsei Medical Journal, vol. 52, no. 4, pp. 553-557, 2011.

[13] H. G. Kwon, J. H. Hong, M. Y. Lee, Y. H. Kwon, and S. H. Jang, "Somatotopic arrangement of the corticospinal tract at the medullary pyramid in the human brain," European Neurology, vol. 65, no. 1, pp. 46-49, 2011. 


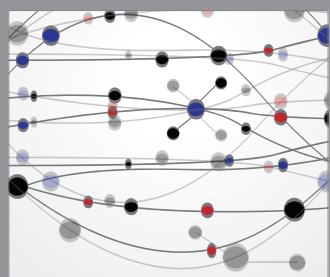

The Scientific World Journal
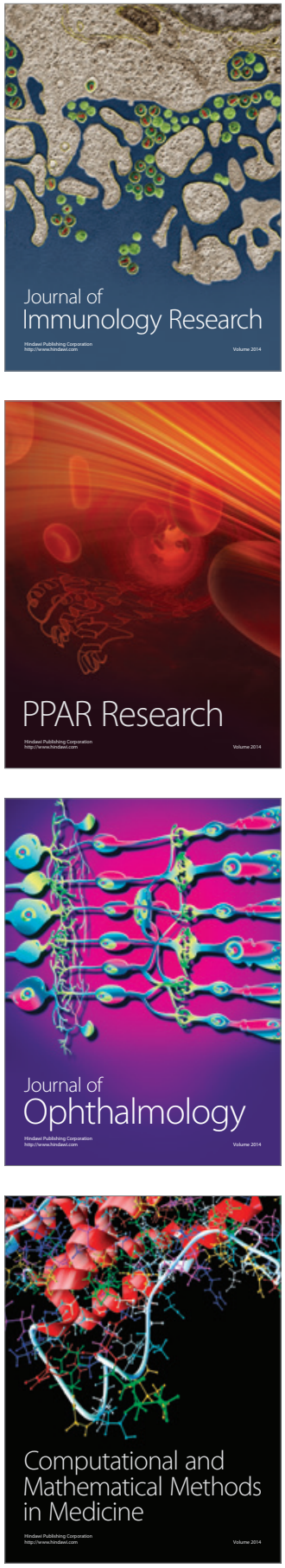

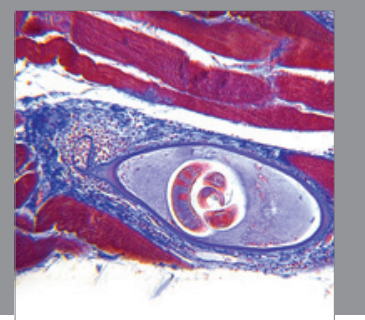

Gastroenterology

Research and Practice
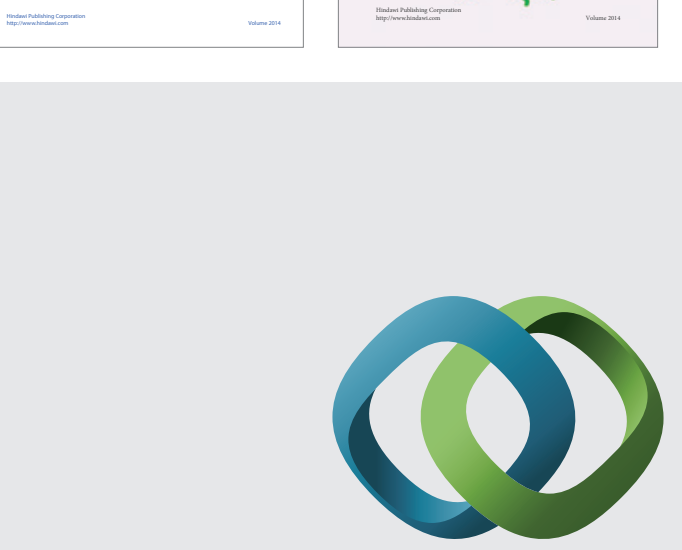

\section{Hindawi}

Submit your manuscripts at

http://www.hindawi.com
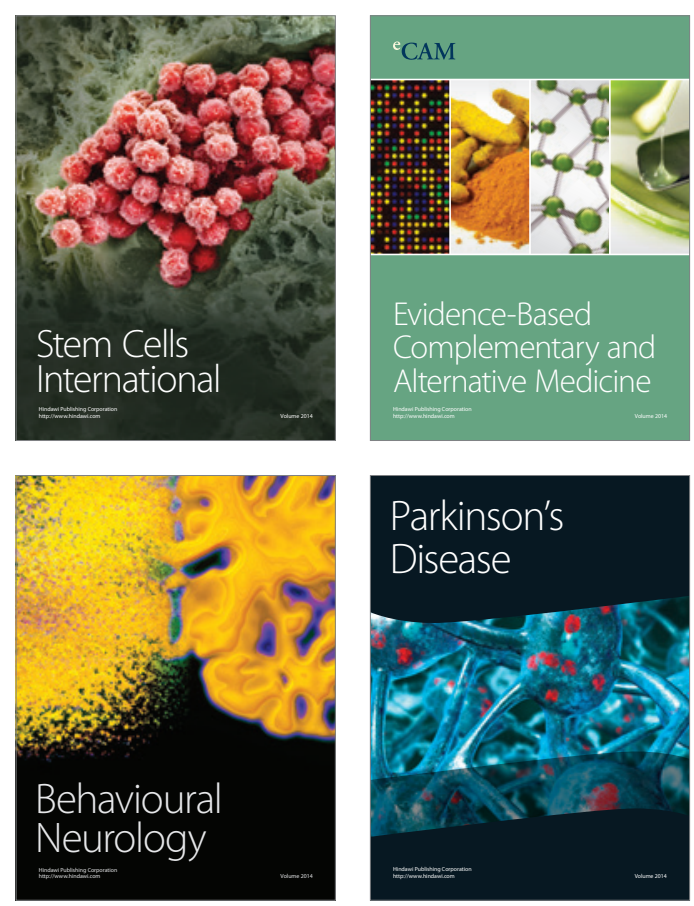

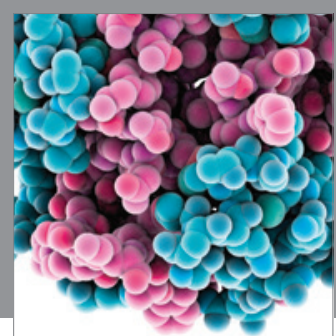

Journal of
Diabetes Research

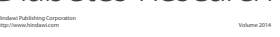

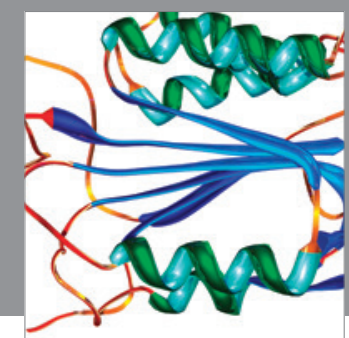

Disease Markers
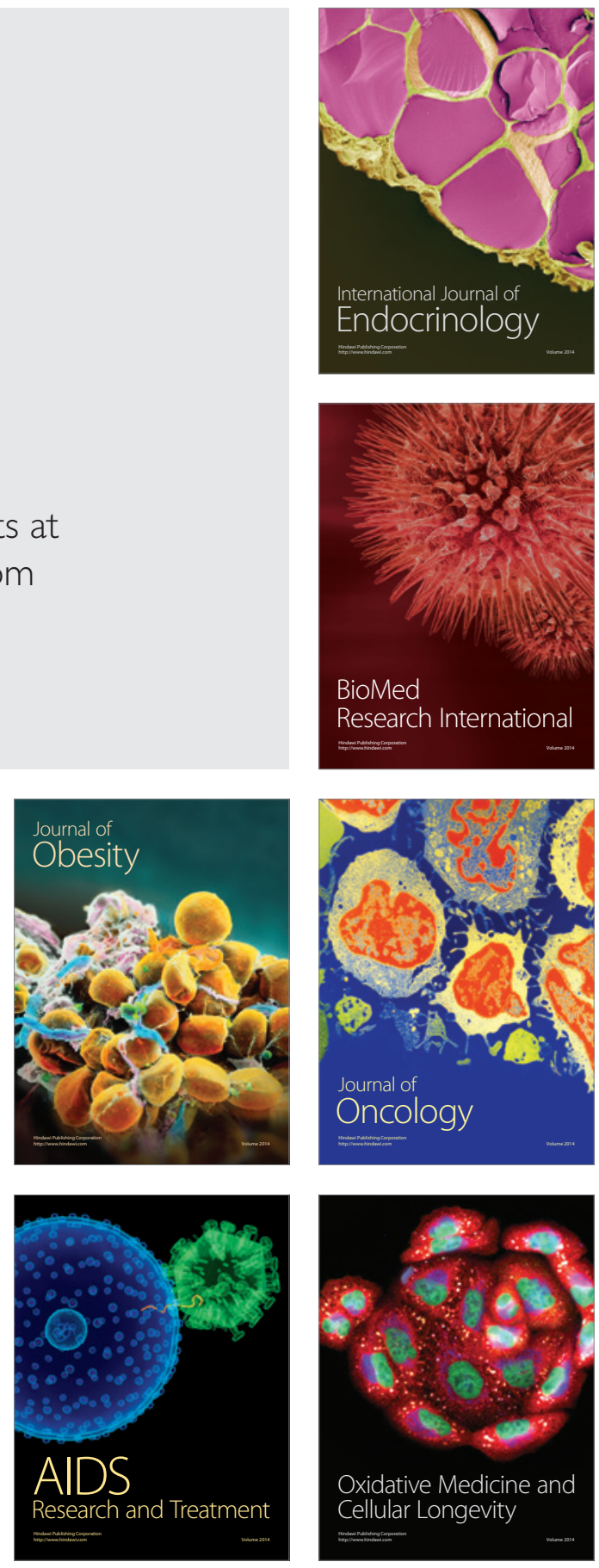